\title{
Evans Syndrome
}

National Cancer Institute

\section{Source}

National Cancer Institute. Evans Syndrome. NCI Thesaurus. Code C61284.

A rare, chronic and relapsing autoimmune disorder of unknown etiology, characterized by the presence of immune thrombocytopenia and autoimmune hemolytic anemia. 